\title{
Developing a Cancer Survivorship Curriculum for Family Medicine Residents: A Needs Assessment
}

\author{
Jane R. Schubart ${ }^{1}$, Niraj J. Gusani ${ }^{2}$, Rena Kass ${ }^{3}$ \& Peter Lewis ${ }^{4}$ \\ ${ }^{1}$ The Pennsylvania State University, College of Medicine, Departments of Surgery, Medicine, \& Public Health \\ Sciences, Hershey, PA \\ ${ }^{2}$ The Pennsylvania State University, College of Medicine, Departments of Surgery \& Public Health Sciences, \\ Hershey, PA \\ ${ }^{3}$ The Pennsylvania State University, College of Medicine, Department of Surgery, Hershey, PA \\ ${ }^{4}$ The Pennsylvania State University, College of Medicine, Department of Family and Community Medicine, \\ Hershey, PA \\ Correspondence: Jane R. Schubart, The Pennsylvania State University, College of Medicine, 500 University \\ Drive, H151, Hershey, PA 17033. Tel: 717-531-1262. E-mail: jschubart@hmc.psu.edu
}

Received: December 23, 2012 Accepted: January 6, 2013 Available online: January 19, 2013

doi:10.11114/jets.v1i1.30

URL: http://dx.doi.org/10.11114/jets.v1i1.30

\begin{abstract}
With the increasing survival of cancer patients, primary care residents must be familiar with the late effects of cancer treatment and be able to offer appropriate survivorship care in partnership with cancer care specialists. To address these paired public health and educational needs, an interdisciplinary group at our institution is developing, implementing, and evaluating an online cancer survivorship curriculum for primary care residents. In the development phase of our survivorship curriculum we administered an online needs assessment survey questionnaire and conducted a focus group interview with the family medicine residents at our institution. Residents indicated that they rarely utilized survivorship care plans or explicitly negotiated a program of shared patient care with the patient's cancer specialists. Less than satisfactory elements of cancer survivorship education were identified. Cancer survivorship care is common in family medicine residency care and opportunities exist to improve education, care, and collaboration.
\end{abstract}

Keywords: continuity of patient care, primary health care, cancer survivors, needs assessment, education, medical

\section{Introduction}

It is estimated that 13.7 million Americans with a history of cancer were alive on January 1, 2012, and that number is expected to approach 18 million by 2022 (Siegel et al., 2012). Almost two-thirds of all cancer patients will survive for five or more years, with much higher rates for many common cancers. With increasing survival for cancer patients (Siegel, Naishadham, \& Jemal, 2012), to a greater extent primary care providers will need to manage and treat the long-term adverse effects of cancer treatment. Also, because the majority of cancer survivors are over age 65, survivorship often occurs against a background setting of comorbid medical conditions (Ogle, Swanson, Woods, \& Azzouz, 2000) with care provided by primary care physicians. In fact, an Institute of Medicine (IOM) survey of over twenty thousand annual ambulatory visits by cancer patients found that the vast majority were treated by primary care physicians, with visits to oncologists a distant second (Hewitt \& Ganz, 2006).

The IOM and others (United States President's Cancer Panel, 2004) have examined the range of medical and psychosocial issues faced by adult cancer survivors, and several oncology-related organizations (e.g., American Society of Clinical Oncology) have developed clinical guidelines to ensure that cancer survivors receive adequate follow-up care. These guidelines include protocols for follow-up and testing, however, it is not clear how to transfer and coordinate survivorship care to primary care physicians in the community where most cancer survivors are being treated (Nissen et al., 2007). Furthermore, while medical school curricula and residency training have traditionally focused on the diagnosis and treatment of cancer, and more recently on its prevention, few have focused on the long-term care of cancer survivors (Ludmerer, 2000; Stoeckle, 2000). 
To address these paired public health and educational needs, an interdisciplinary group at our institution is developing, implementing, and evaluating an interactive, online cancer survivorship curriculum for primary care residents. We anticipate that faculty and administrators will be supportive of the online curriculum because it addresses three of our institutional Strategic Goals for Education. These goals include providing a physically comfortable and intellectually challenging learning environment; teaching students timely and relevant information, utilizing the most appropriate blend of educational modalities and technologies; and using human and financial resources efficiently and responsibly. Students will be able to access the online curriculum from any computer at their own convenience using their institutional account. The site will be intellectually engaging and will include features used to enhance our current learning environments such as email and online discussion features.

Cancer survivorship is a timely and relevant topic to include in the training of primary care physicians. We will use a blend of educational modalities including an introduction to the program during a dedicated session; the online interactive educational module, and use of standardized patients (for both assessment and learning opportunity). Because it can be reused, instruction that is delivered via the Internet is potentially very cost-effective compared to face-to-face instruction. The content will be easy to modify/update and can be used for many years. Additionally, competency-based education is becoming the standard in the training of family medicine residents, with competence redefined to emphasize a multi-dimensional and dynamic nature (Frank et al., 2010), that results from the use of a combination of components in a given situation (Fernandez et al., 2012) rather than mastery of separate components. Given the already full residency curriculum, teaching methods that emphasize synergy and are clinically relevant for busy learners are more likely to succeed. For example, our approach distills the clinical content into simulated cases that model appropriate physician-patient interactions. Online instruction is widely accepted at our institution, and success has been demonstrated by others as well (Kerfoot, Massar, \& Hafler, 2005; Fleiszer \& Posel, 2003; Rowe, Frantz \& Bozalek, 2012).

Our development process is based on Kern's (1998) six-step approach for developing curriculum for medical education (Kern, 1998). Our initial teaching modules address survivorship care regarding breast and colorectal cancer, a specific health problem identified (Step 1). In the development phase of our survivorship curriculum we first assessed the needs of our targeted learners, primary care residents in caring for their patients who have been diagnosed with cancer (Step 2). We administered an online needs assessment survey questionnaire and conducted a focus group interview session with the family medicine residents at our institution. A description of this needs assessment follows.

\section{Method}

\subsection{Participants}

Residents in the Penn State Family \& Community Medicine residency program (2009-2010) were recruited by email to participate in a focus group session and/or an online survey questionnaire. The email contained a link to an online questionnaire. Participation was voluntary. No compensation was provided. Nineteen of the 20 residents participated in the questionnaire survey: 6 first-year residents, 8 second-year, and 5 third-year. Twelve were females and 18 had graduated from a foreign medical school. No other demographic information was collected. All of the residents who answered the survey questionnaire participated in the focus group session.

\subsection{Procedure}

The online survey questionnaire included 98 questions. Answer choices were in multiple-choice and Likert scale formats, with the exception of one free-text question. The survey questionnaire was anonymous.

The one-hour focus group interview session was facilitated by two of the authors (JS and PL; both are skilled facilitators) and was scheduled just prior to a didactic teaching session as part of the ongoing family medicine curriculum. The format was semi-structured, using a template of open-ended questions to guide the discussion. By asking each resident's views on specific topics, quiet participants were given opportunities to share their perspectives.

The study was approved by the Institutional Review Board of Penn State University and by the Good Samaritan Hospital Ethics Committee.

\subsection{Measures}

\subsubsection{Questionnaire}

The items for the questionnaire were generated by the authors: a physician in family medicine (PL); physician/surgeon in gastrointestinal cancer (NG); physician/surgeon in breast cancer (RK); health outcomes 
researcher (JS). Additionally, content was obtained through interactions with colleagues in the Cancer and Primary Care Research International Network (Ca-PRI), an open, multidisciplinary network for researchers in primary cancer care.

\subsubsection{Focus Group}

The first half of the focus group session explored residents' experiences and perceived needs in caring for cancer survivors. They were asked how they knew when a patient had a cancer diagnosis, whether current or previously, and what they do differently, what information they need, and the challenges and barriers to providing optimal care. Other questions were about medical history-taking and obtaining past information about the patient's cancer, "clues" that might help to identify long-term and late effects of treatment, and evaluating the risk for evaluating hereditary susceptibility to cancer. The second half of the session explored the idea of a learning module for a cancer survivorship curriculum.

\section{Results}

\subsection{Survey Questionnaire}

In response to survey questions about any cancer survivorship training received during medical school, less than half of the residents reported receiving training during lectures, small group problem-based learning sessions, OSCE sessions, or working with physicians and healthcare providers, with one exception: working with oncology physicians. When asked to rank their overall ability to provide survivorship care at the conclusion of medical school, approximately half of the residents said medical school training was less than satisfactory in this regard (see Table 1). Involvement and collaboration with cancer specialists increased only slightly from medical school to residency training (see Table 2).

Table 1. Medical school training

\begin{tabular}{|c|c|c|c|c|c|}
\hline \multicolumn{6}{|c|}{ Instruction Received Pertaining to Cancer Survivorship } \\
\hline & & & Yes & No & Don’t recall \\
\hline \multicolumn{3}{|l|}{ During lecture/large group } & $8(44 \%)$ & $8(44 \%)$ & $2(11 \%)$ \\
\hline \multicolumn{3}{|c|}{ During small group, problem-based learning } & 7 (39\%) & $7(39 \%)$ & $4(22 \%)$ \\
\hline \multicolumn{3}{|l|}{ Utilizing standardized patients } & $3(17 \%)$ & $12(67 \%)$ & $3(17 \%)$ \\
\hline \multicolumn{3}{|l|}{ Participating in OSCE exercise } & 7 (39\%) & $9(50 \%)$ & $2(11 \%)$ \\
\hline \multicolumn{3}{|c|}{$\begin{array}{l}\text { Working with or observing family medicine residents providing } \\
\text { survivorship care }\end{array}$} & $6(33 \%)$ & $9(50 \%)$ & $3(17 \%)$ \\
\hline \multicolumn{3}{|c|}{ Family medicine attending physicians } & $8(44 \%)$ & $9(50 \%)$ & $1(6 \%)$ \\
\hline \multicolumn{3}{|l|}{ Oncology attending physicians } & $12(67 \%)$ & $5(28 \%)$ & $1(6 \%)$ \\
\hline \multicolumn{3}{|l|}{ Palliative Care or Hospice } & $6(33 \%)$ & $11(61 \%)$ & $1(6 \%)$ \\
\hline \multicolumn{3}{|l|}{ A chaplain } & $2(11 \%)$ & $15(83 \%)$ & $1(6 \%)$ \\
\hline \multicolumn{6}{|c|}{ At conclusion of medical school, self-rating of overall ability to provide care } \\
\hline & Exceptional & $\begin{array}{l}\text { More than } \\
\text { satisfactory }\end{array}$ & Satisfactory & $\begin{array}{l}\text { Less than } \\
\text { satisfactory }\end{array}$ & Poor/inadequate \\
\hline To pediatric cancer survivors & $1(6 \%)$ & $0(0 \%)$ & $4(22 \%)$ & $7(39 \%)$ & $6(33 \%)$ \\
\hline To adolescent cancer survivors & $0(0 \%)$ & $2(11 \%)$ & $5(28 \%)$ & $5(28 \%)$ & $6(33 \%)$ \\
\hline To adult cancer survivors & $0(0 \%)$ & $2(11 \%)$ & $8(44 \%)$ & $528 \%)$ & $3(17 \%)$ \\
\hline
\end{tabular}


Table 2. Involvement/collaboration with cancer specialists

\begin{tabular}{|c|c|c|c|c|c|}
\hline \multirow{2}{*}{\multicolumn{3}{|c|}{ Instruction Received Pertaining to Cancer Survivorship }} & & & \\
\hline & & & Yes & No & Don't Recall \\
\hline \multicolumn{3}{|l|}{ During lecture/large group } & $7(39 \%)$ & $9(50 \%)$ & $2(11 \%)$ \\
\hline \multicolumn{3}{|l|}{ During morning report } & $5(28 \%)$ & $12(67 \%)$ & $1(6 \%)$ \\
\hline \multicolumn{3}{|l|}{ During hospital rounds } & $14(78 \%)$ & $4(22 \%)$ & $0(0 \%)$ \\
\hline \multicolumn{3}{|l|}{ During outpatient precepting } & $11(61 \%)$ & $7(39 \%)$ & $0(0 \%)$ \\
\hline \multicolumn{3}{|l|}{ During balint } & $7(39 \%)$ & $11(61 \%)$ & $0(0 \%)$ \\
\hline \multicolumn{3}{|l|}{ Utilizing standardized patients } & $2(11 \%)$ & $16(89 \%)$ & $0(0 \%)$ \\
\hline \multicolumn{3}{|l|}{ Participating in OSCE exercise } & $0(0 \%)$ & $18(100 \%)$ & $0(0 \%)$ \\
\hline \multicolumn{3}{|c|}{ Working with family medicine residents providing survivorship care } & $9(50 \%)$ & $9(50 \%)$ & $0(0 \%)$ \\
\hline \multicolumn{3}{|c|}{ Oncology attending physicians } & $5(28 \%)$ & $13(72 \%)$ & $0(0 \%)$ \\
\hline \multicolumn{3}{|l|}{ Palliative Care or Hospice } & $11(61 \%)$ & $7(39 \%)$ & $0(0 \%)$ \\
\hline \multicolumn{3}{|l|}{ A chaplain } & $4(22 \%)$ & $13(72 \%)$ & $1(6 \%)$ \\
\hline \multicolumn{6}{|l|}{ Participating in home visit } \\
\hline \multicolumn{3}{|c|}{ Serving as the primary physician providing survivorship care to adult patients } & $2(12 \%)$ & $14(82 \%)$ & $1(6 \%)$ \\
\hline \multicolumn{3}{|c|}{ Pediatric patients } & $4(24 \%$ & $13(77 \%)$ & $0(0 \%)$ \\
\hline \multicolumn{3}{|l|}{ Adolescent patients } & $3(18 \%)$ & $14(82 \%)$ & $0(0 \%)$ \\
\hline \multicolumn{3}{|l|}{ Prenatal patients } & $1(6 \%)$ & $17(100 \%)$ & $0(0 \%)$ \\
\hline \multicolumn{6}{|l|}{ Rating of teaching/training pertaining to: } \\
\hline \multirow[b]{2}{*}{ Evaluating for recurrence of a primary cancer } & Exceptional & $\begin{array}{c}\text { More than } \\
\text { satisfactory }\end{array}$ & Satisfactory & $\begin{array}{c}\text { Less than } \\
\text { satisfactory }\end{array}$ & $\begin{array}{c}\text { Poor/ } \\
\text { inadequate }\end{array}$ \\
\hline & $0(0 \%)$ & $3(18 \%)$ & $7(41 \%)$ & $5(29 \%)$ & $2(12 \%)$ \\
\hline Screening for a new primary cancer & $0(0 \%)$ & $2(12 \%)$ & $9(53 \%)$ & $5(29 \%)$ & $1(6 \%)$ \\
\hline Genetic testing in family members & $0(0 \%)$ & $1(6 \%)$ & $5(29 \%)$ & $6(35 \%)$ & $5(29 \%)$ \\
\hline Pain control needs & $0(0 \%)$ & $3(18 \%)$ & $12(71 \%)$ & $1(6 \%)$ & $1(6 \%)$ \\
\hline Recognition and treatment of: & & & & & \\
\hline Behavioral health issues & $0(0 \%)$ & $3(18 \%)$ & $10(59 \%)$ & $3(18 \%)$ & $1(6 \%)$ \\
\hline Sexual dysfunction & $0(0 \%)$ & $0(0 \%)$ & $5(29 \%)$ & $9(53 \%)$ & $3(18 \%)$ \\
\hline Sterility/fertility issues & $0(0 \%)$ & $0(0 \%)$ & $5(29 \%)$ & $9(53 \%)$ & $3(18 \%)$ \\
\hline Side effects of chemotherapy & $0(0 \%)$ & $1(6 \%)$ & $10(59 \%)$ & $5(29 \%)$ & $1(6 \%)$ \\
\hline Side effects of surgery & $0(0 \%)$ & $0(0 \%)$ & 7 (41\%) & $9(53 \%)$ & $1(6 \%)$ \\
\hline Side effects of radiation therapy & $0(0 \%)$ & $1(6 \%)$ & $7(41 \%)$ & $8(47 \%)$ & $1(6 \%)$ \\
\hline Recurrence, metastasis, failed treatment & $0(0 \%)$ & $2(12 \%)$ & $10(59 \%)$ & $5(29 \%)$ & $0(0 \%)$ \\
\hline Advance care planning & $1(6 \%)$ & $2(12 \%)$ & $9(53 \%)$ & $5(29 \%)$ & $0(0 \%)$ \\
\hline End of life care & $1(6 \%)$ & $2(12 \%)$ & $10(59 \%)$ & $4(24 \%)$ & $0(0 \%)$ \\
\hline Insurance or financial difficulties & $0(0 \%)$ & $1(6 \%)$ & $6(35 \%)$ & $6(35 \%)$ & $4(24 \%)$ \\
\hline Health care disparities & $0(0 \%)$ & $1(6 \%)$ & $8(47 \%)$ & $6(35 \%)$ & $2(12 \%)$ \\
\hline Caregiver/partner stress & $0(0 \%)$ & $0(0 \%)$ & $9(53 \%)$ & $8(47 \%)$ & $0(0 \%)$ \\
\hline Community support services & $0(0 \%)$ & $2(12 \%)$ & $8(47 \%)$ & $6(35 \%)$ & $2(12 \%)$ \\
\hline Wellness care & $0(0 \%)$ & $1(6 \%)$ & $11(65 \%$ & $5(29 \%)$ & $0(0 \%)$ \\
\hline Overall treatment of: & & & & & \\
\hline Pediatric patients & $0(0 \%)$ & $1(6 \%)$ & $5(29 \%)$ & $8(47 \%)$ & $3(18 \%)$ \\
\hline Adolescent patients & $0(0 \%)$ & $1(6 \%)$ & $5(29 \%)$ & $8(47 \%)$ & $3(18 \%)$ \\
\hline Adult patients & $0(0 \%)$ & $1(6 \%)$ & $10(59 \%)$ & $4(24 \%)$ & $2(12 \%)$ \\
\hline Adult breast cancer survivors & $0(0 \%)$ & $1(6 \%)$ & $11(65 \%)$ & $4(24 \%)$ & $1(6 \%)$ \\
\hline Adult lung cancer survivors & $0(0 \%)$ & $0(0 \%)$ & $13(77 \%)$ & $4(24 \%)$ & $0(0 \%)$ \\
\hline Adult colon cancer survivors & $0(0 \%)$ & $1(6 \%)$ & $12(71 \%)$ & $4(24 \%)$ & $0(0 \%)$ \\
\hline Adult prostate cancer survivors & $0(0 \%)$ & $0(0 \%)$ & $12(71 \%)$ & $5(29 \%)$ & $0(0 \%)$ \\
\hline Adult leukemia/lymphoma survivors & $0(0 \%)$ & $0(0 \%)$ & $9(53 \%)$ & $7(41 \%)$ & $1(6 \%)$ \\
\hline
\end{tabular}


In response to questions about survivorship training during their residency program to date, responses reflect more opportunities to interact with patients who have been diagnosed with cancer, particularly during in-patient hospital rotations and, to a lesser extent, during outpatient precepting experiences. Most residents had not served as the primary physician to a patient who had cancer.

Residents reported feeling more satisfied with training pertaining to pain control needs, depression and other behavioral health issues, and screening for a new primary cancer. Areas of cancer survivorship education rated as less than satisfactory or poor/inadequate by most residents include sexual function issues, sterility/fertility issues, genetic susceptibility testing, side effects of surgery and radiation therapy, insurance or financial difficulties, caregiver stress/burnout, disparities in health care, and community support services (see Table 3).

The vast majority of the primary care residents expressed a preference for a shared model of care for working with cancer specialists where they share a role in discussion of treatment choices, referrals to a new specialist when needed, assessing and managing symptoms, and caring for the medical and emotional needs of the patient, all under the supervision of the oncologist. Sixteen of 19 residents (94\%) preferred this model, yet only 8 said that shared care occurred in actual practice. When asked whether, after a cancer diagnosis, their patients consult them about treatment options and decision-making, 12 residents (71\%) said that this rarely or never occurs. A parallel model of care was reported to be more common (59\%), where the primary care physician continues to follow the patient by managing non-cancer medical problems, and provides support and encouragement (see Table 3).

Table 3. Preferred vs. Actual Model of Care for Working with Cancer Specialists

\begin{tabular}{|c|c|c|}
\hline & Preferred & Common/Actual \\
\hline Sequential & $1(6 \%)$ & $1(6 \%)$ \\
\hline \multicolumn{3}{|l|}{$\begin{array}{l}\text { Patients receive virtually all of their care from specialists after diagnosis } \\
\text { and then return to me after treatment is completed. }\end{array}$} \\
\hline Parallel & $3(18 \%)$ & 10 (59\%) \\
\hline \multicolumn{3}{|l|}{$\begin{array}{l}\text { I continue to follow patients by managing non-cancer medical problems, I } \\
\text { may also provide encouragement and support. }\end{array}$} \\
\hline Shared & 16 (94\%) & $8(47 \%)$ \\
\hline $\begin{array}{l}\text { I share a role in discussing treatment alternatives, referring to new } \\
\text { specialist, and assessing and managing cancer symptoms, as well as taking } \\
\text { care of medical and emotional needs; involved in cancer treatment under } \\
\text { the supervision of the oncologist. }\end{array}$ & & \\
\hline
\end{tabular}

When asked about survivorship care delivered in the outpatient setting, after the patient has completed primary treatment, residents' responses reflected the lack of attention to issues related to long-term or late effects of cancer treatment. Survivorship care is rarely the focus of the visit, and they rarely utilize a cancer guide or care plan. Overall, residents' motivation to provide survivorship care was high, but their confidence to do so was substantially less (see Table 4).

Table 4. Residents’ Motivation and Confidence to Improve Care of Patients with Cancer

\begin{tabular}{lccccccccccc}
\hline & 1 & 2 & 3 & 4 & 5 & 6 & 7 & 8 & 9 & 10 & Rating Average \\
\hline Motivation & 0 & 0 & 0 & 0 & 0 & 0 & 4 & 2 & 3 & 7 & 8.81 \\
Confidence & 0 & 1 & 1 & 0 & 2 & 2 & 2 & 2 & 1 & 5 & 7.25 \\
\hline
\end{tabular}

Scale 1-10 (1 being not motivated -10 being very motivated)

\subsection{Focus Group Session}

Two predominate themes emerged from the discussion. First, residents did not feel that they were sufficiently equipped in terms of the specific clinical knowledge and skills needed to provide optimal care to cancer survivors. As one resident said, "One of the barriers, personally for me, is not being so knowledgeable with all 
the treatment options for cancer and the side effects that we should be watching for." This sentiment was articulated by most of the residents. Another said, "I don't think that I'm prepared for doing this in a hospital setting or in the outpatient setting." Residents discussed their involvement in caring for patients with a cancer diagnosis. They expressed discomfort in sharing information with patients about their particular cancer or advising them about treatment options. This discomfort was heightened when the specialist had not explained the nature and potential side effects of the cancer therapies or discussed prognosis, which was generally the case. Their discomfort extended to post-treatment follow-up care and symptom control.

The second theme expressed by residents was the lack of shared care and feeling isolated in working with oncology specialists, even when they had early involvement at the time of the cancer diagnosis. "The time when they are being treated with chemotherapy or radiation therapy, we seem to kind of lose a bit of touch." In practice residents described a parallel model of care whereby they continued to follow their patients after a cancer diagnosis, but the care was limited to non-cancer medical problems. The barriers to coordinating care with cancer specialists related to accessibility of the specialist, often most needed when the resident was seeing a patient in the exam room. "He's not going to come to see you for cancer issues. He's here for either his hypertension or diabetes or some other issues." Timely communication with specialists was perceived as difficult, and when it occurred was generally via telephone. Written cancer treatment summaries and care plans were lacking. Residents did not feel that their position was not respected. Instead, barriers to shared care and continuity of care related to opportunities to develop relationships with specialists (e.g., busy schedules), systems issues (e.g., comprehensive treatment summaries when many physicians are involved in the patient's care), and their own reticence to take a more active and collaborative role in the cancer patient's care. For example, one resident suggested that, "It would be a good idea if we have more knowledge of resources that are available for cancer patients." Another said, "I was thinking if there is a cancer survivor clinic, that it would be a good idea to be there."

\section{Discussion}

The results from our needs assessment survey questionnaire and focus group study highlight the need to improve medical education addressing care of cancer survivors and the shared care relationships between primary and specialty care providers. Our needs assessment results showed less than satisfactory comfort and practice among Family Medicine residents in providing cancer survivorship care. These results are consistent with other studies; for example, in a survey of 175 PCP's in a large health care system found more than $80 \%$ were uncertain regarding surveillance tests for breast or colorectal cancer, and expressed low comfort in having responsibility for surveillance of cancer recurrence; and more than half rated the transfer of care from oncologist to PCP as fair or poor, even though their institution uses a robust electronic medical record (Nissen et al., 2007). In our study, family medicine residents indicated that they rarely utilized survivorship care plans or explicitly negotiated a program of shared care with the patient's cancer specialists. They voiced concerns about the primary care physician's role and lack of a clear role definition. Effective communication between primary care and specialty care providers emerged as a strong theme. The residents raised issues regarding service delivery, consultation, and continuity of care in the context of improving their ability to deliver survivorship care, as well as the importance of improving their knowledge, skills and confidence in providing care to this growing population.

\subsection{Developing a Cancer Survivorship Curriculum}

The transition from active cancer treatment to post-treatment care is critical to long-term health, yet inclusion of cancer survivorship content in the education and training of primary care physicians is lacking. With the increasing survival of cancer patients, primary care providers must be familiar with the side effects that persist after cancer treatment, as well as the late effects that are absent or subclinical at the end of therapy but manifest later; and they need to be able to offer preventive and/or supportive care. Many potential late effects have been described, largely in convenience samples. For example, possible late effects of breast cancer treatment include arm lymphedema, premature menopause, osteoporosis, hot flashes, weight gain, cardiovascular disease, fatigue, cognitive impairment, psychosocial distress, yet there is limited empirical information to guide physicians (Burnstein \& Winer, 2000). Colorectal cancer patients often experience bowel dysfunction, sexual dysfunction, peripheral neuropathy, and psychosocial distress after treatment has ended (Hewitt \& Ganz, 2006).

As part of our institution's survivorship care program (Gusani et al., 2009), to improve the ability of family physicians to provide patient-centered cancer survivorship care in partnership with cancer specialists, we are developing, implementing, and evaluating an interactive online cancer survivorship curriculum for family medicine residents. Online learning modules offer advantages over traditional teaching methods, and online materials have been generally well-accepted by primary care residents in prior studies (Skye, Wimsatt, 
Master-Hunter, \& Locke, 2011). Residents can receive didactics at times and places most convenient to them; content can be tailored to the learner's needs; and material is easily accessible and updated (Adler \& Johnson, 2000; Cook, 2006).

Our online modules address survivorship care regarding breast and colorectal cancer with the goal of improved survivorship education, care, and collaboration. Modules include didactic teaching — for breast cancer topics include tamoxifen and drug interactions; vaginal bleeding on tamoxifen, hot flashes, hereditary breast syndromes, psychosocial functioning. Throughout the module content, we incorporate working with the oncologist and a shared care model. For colorectal cancer, our module covers post-operative and post-chemotherapy side-effects and changes, concerns about recurrence, and common questions regarding diet, exercise, and risk-reduction.

Given the growing population of people who survive cancer, care of the cancer survivor is an important competency to be mastered by family and primary care medical residents who provide complementary care (in addition to the care provided by oncologists/surgeons) and ease the transition from cancer patient to cancer survivor while maintaining basic health and preventative care. Often this care is compromised because patients may not see their primary care physicians for months or years while receiving active cancer treatment. This competency is best mastered in the primary care clinic setting; however, as our study results show residents do not always have sufficient practice opportunity. Our online curriculum provides education in the important individual components of cancer survivorship care within the framework of case studies that emphasize the real challenges that primary care physicians encounter in providing care to cancer patients in partnership with cancer specialists.

\section{Conclusion}

The results from our needs assessment survey questionnaire and focus group study suggest that cancer survivorship care is common in family medicine residency care and that opportunities exist to improve survivorship education and shared care relationships between primary and specialty care providers. The care of cancer patients is often complex, involving multiple transitions at various stages of treatment between settings and providers. As others have pointed out, care of cancer survivors can be enhanced by the continued involvement of primary care physicians to include discussions with patients about the diagnosis and decisions about treatment (Siminoff \& Step, 2005), as well as treating non-cancer disease, providing psychological support, continuing appropriate preventative care, and recognizing and managing (or co-managing) complications of the cancer and treatment (Smith \& Toonen, 2007; Sunga, Eberl, Oeffinger, Hudson, \& Mahoney, 2005). In integrating cancer care across providers, the shared care model (Smith, Allwright, \& O’Dowd, 2007) has received the most attention - in this model, specialist and primary care physicians, along with other health professionals, jointly participate in delivering coordinated cancer care.

\section{References}

Adler, M. D., \& Johnson, K. B. (2000). Quantifying the literature of computer-aided instruction in medical education. Academic Medicine: Journal of the Association of American Medical Colleges, 75(10), 1025-1028.

Burstein, H. J., \& Winer, E. P. (2000). Primary care for survivors of breast cancer. New England Journal of Medicine, 343(15), 1086-1094. http://dx.doi.org/10.1056/NEJM200010123431506

Cook, D. A. (2006). Where are we with Web-based learning in medical education? Medical Teacher, 28(7), 594-598. http://dx.doi.org/10.1080/01421590601028854

Fernandez, N., Dory, V., Ste-Marie, L., Chaput, M., Charlin, B., \& Boucher, A. (2012). Varying conceptions of competence: an analysis of how health sciences educators define competence.Medical Education, 46(4), 357-365. http://dx.doi.org/10.1111/j.1365-2923.2011.04183.x

Fleiszer, D. M., \& Posel, N. H. (2003). Development of an undergraduate medical curriculum: the McGill experience. Academic Medicine, 78(3), 265-269. http://dx.doi.org/10.1097/00001888-200303000-00005

Frank, J. R., Snell, L. S., Cate, O. T., Holmboe, E. S., Carraccio, C., Swing S. R., ... Harris, K. A. (2010). Competency-based medical education: theory to practice. Medical Teacher, 32(8), 638-645. http://dx.doi.org/10.3109/0142159X.2010.501190

Gusani, N. J., Schubart, J. R., Wise, J., Farace, E., Green, M. J., Jiang, Y., Kimchi, E. T., \& Staveley-O’Carroll, K. F. (2009). Cancer survivorship: a new challenge for surgical and medical oncologists. Journal of General Internal Medicine, 24 Suppl 2, S456-S458. http://dx.doi.org/10.1007/s11606-009-1010-0 
Hewitt, M., \& Ganz, P. A, eds. (2006). From cancer patient to cancer survivors. Lost in translation: an American society of clinical oncology and institute of medicine symposium. Washington, DC: The National Academies Press.

Kerfoot, B. P., Massar, B. A., \& Hafler, J. P. (2005). Influence of new educational technology on problem-based learning at Harvard Medical School. Medical Education, 39(4), 380-387. http://dx.doi.org/10.1111/j.1365-2929.2005.02105.x

Kern, D. E., Thomas, P. A., Howard, D. M., \& Bass, E. B. (1998). Curriculum development for medical education: asix-step approach. Baltimore, MD: Johns Hopkins University Press.

Ludmerer, K. M. (2000). Time and medical education. Annals of Internal Medicine, 132(1), 25-28.

Nissen, M. J., Beran, M. S., Lee, M. W., Mehta, S. R., Pine, D. A., \& Swenson, K. K. (2007). Views of primary care providers on follow-up care of cancer patients. Family Medicine, 39(7), 477-482.

Ogle, K. S., Swanson, G. M., Woods, N., \& Azzouz, F. (2000). Cancer and comorbidity: redefining chronic diseases. Cancer, 88(3), 653-663. http://dx.doi.org/10.1002/(SICI)1097-0142(20000201)88:3<653::AID-CNCR24>3.0.CO;2-1

Rowe, M., Frantz, J., \& Bozalek, V. (2012). The role of blended learning in the clinical education of healthcare students: A systematic review. Medical Teacher, 34(4), e216-e221. http://dx.doi.org/10.3109/0142159X.2012.642831

Siegel, R., Desantis, C., Virgo, K., Stein, K., Mariotto, A., Smith, T., ... Ward, E. (2012). Cancer treatment and survivorship statistics, 2012. CA: A Cancer Journal for Clinicians, 62(4), 220-241. http://dx.doi.org/10.3322/caac.21149

Siegel, R., Naishadham, D., \& Jemal, A. (2012). Cancer statistics, 2012. CA: A Cancer Journal for Clinicians, 62(1), 10-29. http://dx.doi.org/10.3322/caac.20138

Siminoff, L. A., \& Step, M. M. (2005). A communication model of shared decision making: accounting for cancer treatment decisions. Health Psychology: Official Journal of the Division of Health Psychology, American Psychological Association, 24(4 Suppl), S99-S105. http://dx.doi.org/10.1037/0278-6133.24.4.S99

Skye, E. P., Wimsatt, L. A., Master-Hunter, T. A., \& Locke, A.B. (2011). Developing online learning modules in a family medicine residency. Family Medicine, 43(3), 185-192.

Smith, S. M., Allwright, S., \& O'Dowd, T. (2007). Effectiveness of shared care across the interface between primary and specialty care in chronic disease management. Cochrane Database Systems Review, (3):CD004910.

Smith, G. F., \& Toonen, T. R. (2007). Primary care of the patient with cancer. American Family Physician, 75(8), 1207-1214.

Stoeckle, J. D. (2000). The market pushes education from ward to office, from acute to chronic illness and prevention: will case method teaching-learning change? Archives of Internal Medicine, 160(3), 273-280. http://dx.doi.org/10.1001/archinte.160.3.273

Sunga, A. Y., Eberl, M. M., Oeffinger, K. C., Hudson, M. M., \& Mahoney, M. C. (2005). Care of cancer survivors. American Family Physician, 71(4), 699-706.

United States President's Cancer Panel. (2004). Living beyond cancer: finding a new balance: President's Cancer Panel 2003-2004 annual report. Bethesda, MD: National Cancer Institute, National Institutes of Health, U. S. Department of Health and Human Services.

\section{(c)) EY}

This work is licensed under a Creative Commons Attribution 3.0 License. 